\title{
Short chain fatty acids in the terminal ileum accelerate stomach to caecum transit time in the rat
}

\author{
A Richardson, A T Delbridge, N J Brown, R D E Rumsey, N W Read
}

\begin{abstract}
We have previously shown that infusion of triglycerides and long chain fatty acids into the ileum of humans and rats delays small bowel transit time. The present studies have investigated the effect on the stomach to caecum transit time of a baked bean meal of the ileal infusion of $20 \mathrm{mM}, 50 \mathrm{mM}$, and $100 \mathrm{mM}$ acetic, butyric, hexenoic, and caprylic acids in rats. After an 18 hour fast either a control or a short chain fatty acid (SCFA) solution (pH 6.5) was infused into the ileum for 30 minutes $(0.3 \mathrm{ml} /$ hour $)$. A test meal was given by gavage and the infusion continued for a further 150 minutes. The arrival of the meal in the colon was signalled by a rise in the exhaled hydrogen concentration. Acetic acid $(20 \mathrm{mM}, 50 \mathrm{mM}$, $100 \mathrm{mM})$, butyric acid (100 $\mathrm{mM})$, and caprylic acid $(100 \mathrm{mM})$ produced a significant acceleration of transit which was inversely proportional to SCFA chain length. In a separate experiment, infusion of $100 \mathrm{mM}$ acetic acid, the most potent SCFA, into an isolated ileal Thiry-Vella loop failed to accelerate transit of the test meal. Our results suggest that SCFAs accelerate transit via a local enteric reflex.
\end{abstract}

Infusion of emulsions of triglyceride and long chain fatty acids (LCFA) into the terminal ileum of human volunteers delays transit of a test meal through the stomach ${ }^{1}$ and small intestine ${ }^{2-4}$ and suppresses propagated motor activity in the small intestine. ${ }^{5}$ A similar phenomenon can be shown in the rat; we have recently shown that infusion of long chain fatty acids $(\mathrm{Cl}, \mathrm{C18}$, and C22) delays stomach to caecum transit time in that species. ${ }^{6}$ Recent studies have suggested that short chain fatty acids (SCFA) may act on the ileum to increase propulsive motor activity. ${ }^{78}$ The aim of this study was to investigate the effect of a range of SCFAs on the stomach to caecum transit time of a baked bean test meal in the rat, using a breath hydrogen technique modified for use with small mammals. ${ }^{9}$

TABLE I Electrolyte composition and osmolality of test solutions

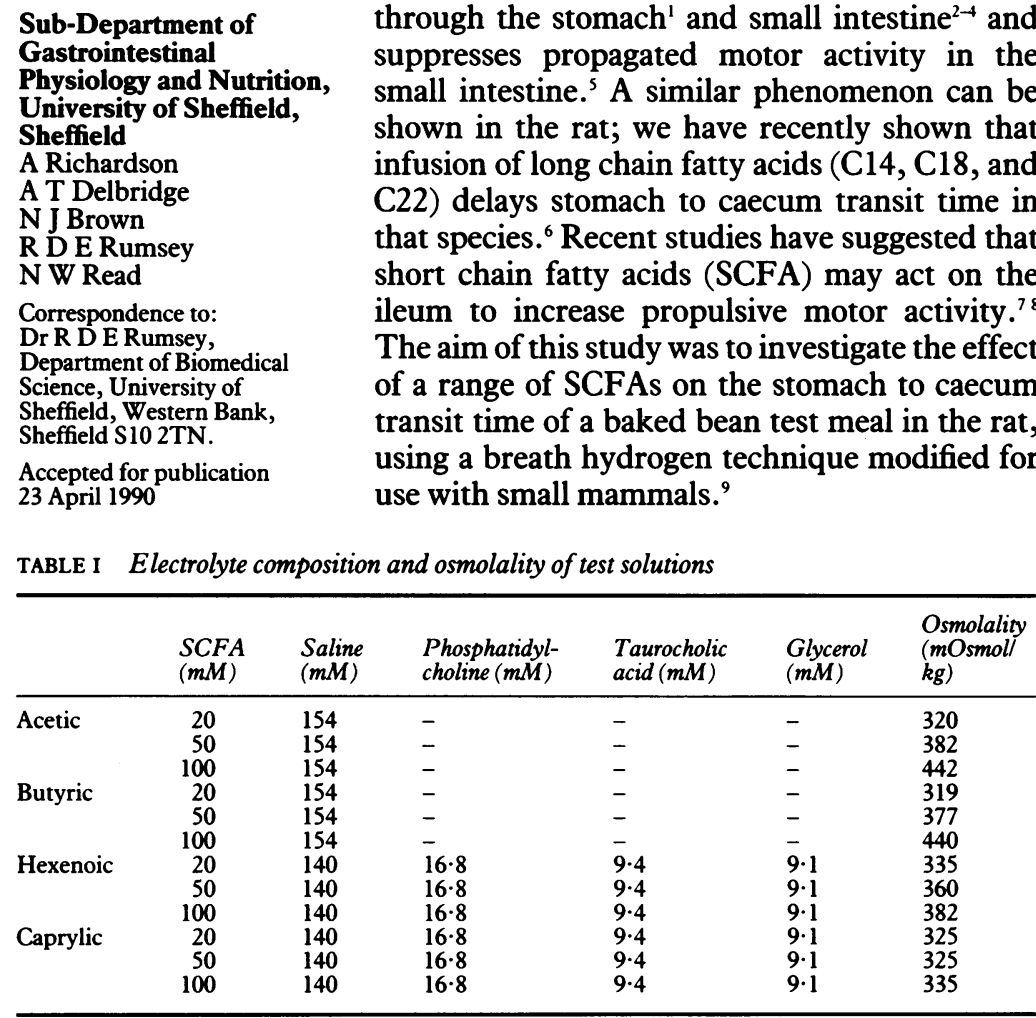

Methods

EXPERIMENTAL DESIGN

The effect of the ileal infusion of a variety of SCFAs on the stomach to caecum transit time of a homogenised baked bean meal was assessed by measurement of exhaled hydrogen concentration. Solutions of $20 \mathrm{mM}, 50 \mathrm{mM}$, and $100 \mathrm{mM}$ acetic acid, butyric acid, hexenoic acid, and caprylic acid were infused into the ileum of 17 male albino rats $(300 \mathrm{~g})$ that had normal intestinal continuity. In addition, the most potent SCFA solution ( $100 \mathrm{mM}$ acetic acid) was infused into an isolated Thiry-Vella loop of ileum in six rats. The rats were allowed free access to food (Diet 86, Oxoid, London) until 18 hours before an experiment, with water available at all times.

\section{SURGICAL PROCEDURE}

Seventeen rats were implanted with a plastic cannula (Silastic ID 0.02 in, OD 0.037 in, Dow Corning Corp, Medical Products, Midland, Michigan, USA) $25 \mathrm{~cm}$ in length, under barbiturate anaesthesia (Sagatal $600 \mathrm{mg} / \mathrm{kg}$, May and Baker Limited, Dagenham, UK). The abdomen was opened via a midline incision and the cannula was inserted into the ileal lumen $20 \mathrm{~cm}$ proximal to the ileo-caecal valve via a stab wound. The intestinal wound was closed around the cannula by a purse-string suture. Sufficient cannula was left free in the abdominal cavity to allow full mobility of the gastrointestinal tract. The abdominal wall and the skin were separately closed using a sterile braided silk suture 5-0 (Mersilk, Ethicon, Edinburgh, Scotland, UK). The cannula was tunnelled subcutaneously from an abdominal stab wound to the midscapular region where it was brought to the surface via a cutaneous puncture wound. A square of nylon mesh, previously secured $2-3 \mathrm{~cm}$ from the end of the cannula with silicon glue (Medical adhesive type A, Dow Corning Corp, Medical Products, Midland, Michigan, USA), formed an anchorage point, as the damaged subcutaneous tissues regenerated forming a platform over the mesh. Each rat was allowed one week to recover from surgery before any experimental procedures were carried out. A small volume of isotonic saline was infused daily through the cannula to ensure patency.

Six rats were prepared with isolated ThiryVella loops using the same operative procedure as above except that a $7 \mathrm{~cm}$ (approximately $1 / 10$ of the small intestine) segment of ileum was located around the cannula and resected. The severed ends of the resected segment (with the mesentery intact) were brought to the abdominal surface through two individual stab wounds and a chronic Thiry-Vella fistula was established with 
two muco-cutaneous stomata. Alimentary continuity was restored by end to end anastomosis of the ileum proximal and distal to the resected segment. The cannula was then brought to the surface as previously described.

\section{PREPARATION OF THE TEST SUBSTANCES}

Four SCFAs - acetic acid (C:2), butyric acid $(\mathrm{C}: 4)$, hexenoic acid $(\mathrm{C}: 6)$, and caprylic acid (C:8) - were tested at $20 \mathrm{mM}, 50 \mathrm{mM}$, and $100 \mathrm{mM}$ concentrations. Table I shows the exact electrolyte composition and osmolality of each test solution. Being water soluble, acetic acid and butyric acid were dissolved in isotonic saline. The less water soluble, hexenoic acid and caprylic acid, were emulsified on ice by ultrasound (W-380, Heat Systems - Ultrasonics Inc, Farmingdale, New York 11735, USA). The emulsifying solution contained $140 \mathrm{mM}$ sodium chloride (Travenol Laboratories Limited, Thetford, Norfolk, UK), $16.8 \mathrm{mM}$ L-alpha-phosphatidyl choline (Sigma Chemical Co, St Louis, MO, USA), $9 \cdot 1 \mathrm{mM}$ glycerol (Sigma Chemical Co), and $9.4 \mathrm{mM}$ taurocholic acid (Sigma Chemical Co). The resulting solution was adjusted to $\mathrm{pH} 6.5$ with sodium hydroxide.

\section{PREPARATION OF THE TEST MEAL}

Californian white beans (H J Heinz Co Ltd, Hayes, Middlesex, UK) were washed to remove the tomato sauce, and homogenised with a little water. Lactose (May and Baker Ltd, Dagenham, UK) was added as an additional source of carbohydrate $-1 \mathrm{~g}$ for every $10 \mathrm{ml}$ of homogenate.

\section{EXPERIMENTAL PROTOCOL}

Experiments were performed on batches of six rats. The effects on stomach to caecum transit time of infusions of acetic acid and butyric acid were compared with the control infusions of isotonic saline, while the stomach to caecum transit times obtained from infusion of hexenoic acid and caprylic acid were compared with control infusions of the emulsifying solution. The control experiments were repeated at the end of the study and an average transit time was taken for each rat. Rats were permitted a rest of at least two days between experiments.

After starvation for 18 hours, the rats were placed in Bolman restraining cages and connected to infusion pumps (Braun, Germany) via plastic tubing (Portex pp30) and a metal connector, which was inserted into the free end of the cannula. Solutions were infused into the ileum at a rate of $0.3 \mathrm{ml} /$ hour. Thirty minutes after beginning the infusion the rats were removed from the restraining cages, gavaged with $5 \mathrm{ml}$ of the bean/lactose meal, and placed in specially designed perspex chambers. The infusion tube was attached to a pulley and counterweight system to allow the rat free movement within the chamber. The infusion was continued for a further 150 minutes after gavage.

The perspex chambers provided a controlled environment from which hydrogen concentrations could be monitored and solutions could be infused without disturbing the animals. Pumps continually drew room air into the chambers at a constant rate of $100 \mathrm{ml} / \mathrm{minute}$ and evacuated gas to the atmosphere through perspex rods running the length of the chambers. The gases within each chamber were mixed continuously by a small fan at the top of a perspex tower, which contained soda lime and silica gel (BDH Chemicals Ltd, Poole, UK) to absorb carbon dioxide and water vapour respectively. Every 10 minutes a solenoid valve switched the flow of gas from the first chamber to a polarographic hydrogen monitor (GMI Medical Ltd, Renfrew, Scotland) previously calibrated with a standard gas mixture. Each chamber was sampled in turn for one minute, and the data were used to plot a hydrogen profile for each rat throughout the experiment.

The stomach to caecum transit time of the head of the test meal was defined as the time from gavage to an increase in the hydrogen concentration of the rat's environment of at least two parts per million (ppm) above basal values that was sustained for at least three successive readings.

\section{STATISTICAL ANALYSIS}

After using Rankit plots to assure a normal distribution of data, a Student's paired $t$ test was used to assess the degree of statistical significance between the stomach to caecum transit times obtained for each rat for each treatment, and their appropriate controls. The percentage decrease in transit time was calculated for each rat for each treatment and Mann-Whitney $U$ tests were performed to assess the degree of significance between the effects of different concentrations of the same SCFA. The mean percentage decrease in transit time for each treatment was used to plot a regression line to show the relation between SCFA chain length and stomach to caecum transit time for each concentration.

\section{Results}

There was no significant difference between the stomach to caecum transit times obtained during control infusions of saline at the start and end of the study (mean (SE) $118 \cdot 2(3 \cdot 6)$ minutes, $n=17$ $v 115.0(4 \cdot 2)$ minutes, $\mathrm{n}=12)$. Similarly there was no significant difference between transit times produced during infusion of saline and the emulsifying solution (111·8 (4.0) minutes).

TABLE II Results of ileal infusions of short chain fatty acids on stomach to caecum transit time (SCTT). Values, mean $(S E)$

\begin{tabular}{lrllll}
\hline Fatty acid & $m M$ & No & Control SCTT & Test SCTT & $p$ \\
\hline Acetic & 20 & 6 & $125 \cdot 0(5 \cdot 8)$ & $75 \cdot 0(9 \cdot 2)$ & $<0 \cdot 01$ \\
& 50 & 5 & $120 \cdot 0(8 \cdot 4)$ & $68 \cdot 0(11 \cdot 1)$ & $<0 \cdot 05$ \\
& 100 & 6 & $125 \cdot 0(5 \cdot 8)$ & $50 \cdot 0(2 \cdot 6)$ & $<0 \cdot 001$ \\
Butyric & 20 & 5 & $116 \cdot 0(8 \cdot 5)$ & $88 \cdot 0(11 \cdot 6)$ & NS \\
& 50 & 6 & $116 \cdot 7(7 \cdot 6)$ & $93 \cdot 3(13 \cdot 1)$ & NS \\
Hexenoic & 100 & 6 & $120 \cdot 0(3 \cdot 2)$ & $76 \cdot 7(12 \cdot 6)$ & $0 \cdot 05$ \\
& 20 & 6 & $115 \cdot 8(4 \cdot 4)$ & $103 \cdot 3(4 \cdot 2)$ & NS \\
& 50 & 6 & $121 \cdot 7(7 \cdot 0)$ & $105 \cdot 0(12 \cdot 8)$ & NS \\
Caprylic & 100 & 6 & $122 \cdot 5(2 \cdot 1)$ & $98 \cdot 3(12 \cdot 8)$ & NS \\
& 20 & 6 & $121 \cdot 7(7 \cdot 0)$ & $123 \cdot 3(22 \cdot 5)$ & NS \\
& 50 & 6 & $121 \cdot 7(7 \cdot 0)$ & $116 \cdot 7(8 \cdot 4)$ & NS \\
& 100 & 8 & $117 \cdot 5(5 \cdot 3)$ & $81 \cdot 3(6 \cdot 1)$ & $<0 \cdot 01$ \\
\hline
\end{tabular}


Regression analysis and statistical significance of the relation between short chain fatty acid chain length and the percentage decrease in stomach to caecum transit time at the $20 \mathrm{mM}, 50 \mathrm{mM}$ and $100 \mathrm{mM}$ concentrations.

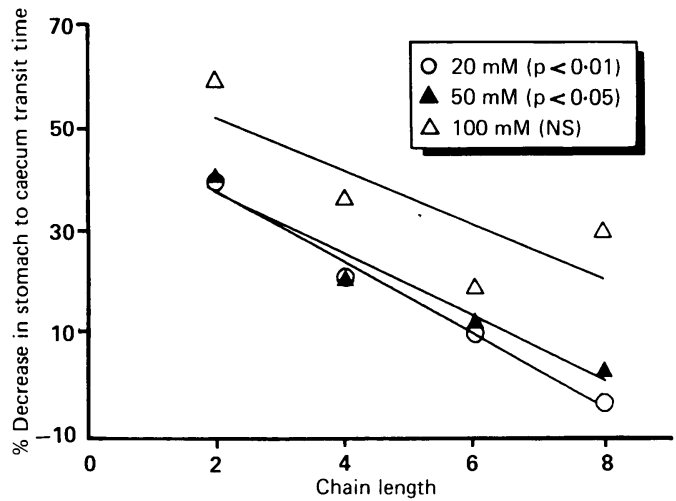

Table II shows that the ileal infusion of all three concentrations of acetic acid produced significant decreases in the transit time of the head of the test meal: $20 \mathrm{mM}(\mathrm{p}<0.01), 50 \mathrm{mM}$ $(\mathrm{p}<0.05)$, and $100 \mathrm{mM}(\mathrm{p}<0.001)$. The decrease in transit time with the $100 \mathrm{mM}$ solution was significantly greater than with $20 \mathrm{mM}$ but not with $50 \mathrm{mM}$ acetic acid. Significant decreases in transit time were only achieved with the highest concentrations $(100 \mathrm{mM})$ of butyric acid $(p<0.05)$ and caprylic acid $(p<0.01)$. The decrease in transit time with $100 \mathrm{mM}$ caprylic acid was significantly greater than with $50 \mathrm{mM}$ caprylic acid. The infusion of $100 \mathrm{mM}$ acetic acid into isolated Thiry-Vella loops did not significantly accelerate the transit time of the head of the baked bean meal when compared with a control infusion of saline (control $v$ test: 90.0 $(8 \cdot 2)$ minutes $v 88 \cdot 3(6 \cdot 5)$ minutes).

The figure shows a strong correlation between SCFA chain length and the acceleration of transit at the $20 \mathrm{mM}(\mathrm{p}<0.01)$ and $50 \mathrm{mM}$ $(p<0.05)$ concentrations.

\section{Discussion}

Our results have shown that the infusion of SCFAs into the ileum of rats significantly decreases the stomach to caecum transit time of the head of a test meal, and this effect is greater with higher concentrations and shorter chain lengths. All solutions were buffered to $\mathrm{pH} 6 \cdot 5$, so it is unlikely that the effects on transit time are related to $\mathrm{pH}$.

It is clear from these results that the effect of ileal infusion of SCFAs is noticeably different from the effect of LCFAs in the same model. Perhaps this has a biological significance: LCFAs and SCFAs enter the small intestine from different sources. Long chain fatty acids come from fats that are ingested as part of a meal, and their presence in the terminal ileum delays transit and would be expected to enhance the absorption of that meal. ${ }^{3}$ Short chain fatty acids are present only in small concentrations in fresh food and are distasteful to most people, but they are produced in high concentrations by bacterial fermentation, which takes place predominantly in the colon. ${ }^{10}$ Suspensions of colonic contents infused into the canine ileum increase propulsive motor activity" : a similar effect was produced by infusing SCFAs into the canine ileum ${ }^{7}$ and the human ileum. ${ }^{8}$ In both our experiments, and in those of Kamath $e t a l,{ }^{7}$ greater effects were seen with SCFAs of shorter chain length. It could be suggested that the relation between chain length and the percentage decrease in transit time may reflect differences in SCFA solubilisation. The emulsified SCFAs may be held within the lipid phase of the infusate, whereas the easily soluble acetic acid will be more freely available. Instillation of $100 \mathrm{ml}$ of a $3 \%$ vinegar solution (acetic acid) into the stomach of dogs produced giant migrating contractions in the small intestine. ${ }^{12}$ This suggests that any region of the small intestine may respond to the presence of SCFAs, although in this study it is likely that the acceleration of transit occurred in the ileum.

It is noteworthy that the types of fatty acid and concentration range that produce the motor effects in the small intestine match those produced by bacterial fermentation in the caecum. The total SCFA concentration of the rat caecum falls within the range 103-190 $\mathrm{mM}$; of which acetate, propionate, and butyrate account for $61 \%, 25 \%$, and $14 \%$ respectively. ${ }^{13}$ It has been suggested $^{8}$ that the small intestinal motor response to SCFAs may be a physiological mechanism for clearing refluxed colonic material from the small intestine, in much the same way that secondary peristalsis clears acid reflux from the lower oesophagus. ${ }^{1+}$

The observation that $100 \mathrm{mM}$ acetic acid, the most potent substance tested, failed to produce a similar effect when infused into an isolated ileal Thiry-Vella loop suggests that the acceleration of transit is produced by a local action in the ileum. It is possible that only the terminal ileum responds to the presence of SCFAs and that a fistula created from more proximal ileum would not respond. As mentioned previously, however, Sarna's work ${ }^{12}$ suggests that this is not the case. Therefore, it is reasonable to assume that infusion of SCFAs into the fistulae does not elicit signals to regulate transit time but may increase motility of the fistulae. In this respect, it differs from the action of LCFAs, which produce a change in gastrointestinal transit even when infused into a loop of ileum. ${ }^{15}$ Since the propulsive motor patterns induced by infusion of SCFAs can be blocked by local anaesthetics, ${ }^{16}$ it seems likely that they activate a local enteric reflex to induce propulsive motor activity and clear luminal contents.

This work was presented in abstract form at the meeting of the British Society of Gastroenterology, Dublin, 1989.

We gratefully acknowledge the financial support of $\mathrm{Kab}$ Invent, Stockholm, Sweden.

1 Welch IM, Cunningham KM, Read NW. Regulation of gastric emptying by ileal nutrients in humans. Gastroenterology 1988; $94: 401-4$.

2 Read NW, McFarlane A, Kinsman RI, et al. Effect of infusion of nutrient solutions into the ileum on gastrointestinal transit and plasma levels of neurotensin and enteroglucagon. Gastroenterology 1984; 86: 274-80.

3 Holgate AM, Read NW. Effect of ileal infusion of Intralipid on gastrointestinal transit, ileal flow rate and carbohydrate absorption in humans after ingestion of a liquid meal. Gastroenterology 1985; 86: 1005-11.

4 Spiller RC, Trotman RF, Higgins BE, et al. The ileal brakeinhibition of jejunal motility after ileal perfusion in man. $G u$ 1984; $25: 265-74$.

5 Welch IM, Worlding J. The effect of ileal infusion of lipid on motility in humans after ingestion of a viscous non-nutrien meal. F Physiol (Lond) 1986; 378: 12P.

6 Brown NJ, Richardson A. Effect of ileal infusion of fatty acids varying in chain length and saturation on stomach to caecum transit time (SCTT) in the rat. $\mathcal{F}$ Physiol (Lond) 1987; 396 20P.

7 Kamath PS, Hoepfner MT, Phillips SF. Short chain fatty acids stimulate motility of the canine ileum. Am F Physio 1987; 253 (4) Pt 1: G427-33. 
8 Kamath PS, Phillips SF, Zinsmeister AR. Short chain fatty acids stimulate ileal motility in humans. Gastroenterology 1988; 95: 1496-502.

9 Brown NJ, Rumsey RDE, Read NW. Adaptation of hydrogen analysis to measure stomach to caecum transit time in the rat. Gut 1987; 28: 849-54.

10 Miller TL, Wolin MJ. Fermentation of saccharolytic intestinal bacteria. Am f Clin Nutr 1979; 32: 164-72.

11 Kruis W, Azpiroz F, Phillips SF. Contractile patterns and transit of fluid in canine terminal ileum. Am F Physiol 1985; 249: G264-70

12 Sarna SK. ECA independent "giant migrating contractions" of small intestine. Gastroenterology 1984; 86: 1232.
13 Remesy C, Demigne C. Partition and absorption of volatile fatty acids in the alimentary canal of the rat. Anneales de Recherches Veterinaires 1976; 7: 39-55.

14 Dent J, Dodds WJ, Friedman PH, et al. Mechanisms of gastroesophageal reflux in recumbent asymptomatic human subjects. $\mathcal{F}$ Clin Invest 1980; 65: 256-67.

15 Brown NJ, Richardson A, Rumsey RDE, Read NW. Effects of ileal infusions of various lipids and detergents on stomach to caecum transit time in the rat. Gut 1987;28: 1355 .

16 Kamath PS, Phillips SF. Initiation of motility in canine ileum by short chain fatty acids and inhibition by pharmacological agents. Gut 1988; 29: 941-8.

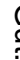

